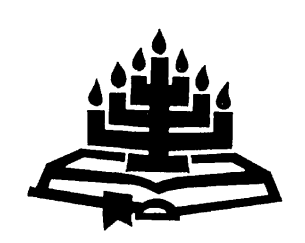

\title{
Veni, veni, o Oriens ... die erediens as kommunikatiewe handeling gerig op oriëntering, uitdrukking, verandering en verbintenis
}

\author{
Elsabé Kloppers \\ Departement Praktiese Teologie \\ Universiteit van Suid-Afrika \\ PRETORIA \\ E-pos: iksa@mweb.co.za
}

\begin{abstract}
Veni, veni, o Oriens ... the worship service as communicative action aimed at orientation, expression, change and commitment

Through symbolic communication the experience of faith can be brought about and the Christian tradition actively transmitted in a worship service. In this article it is argued that in the worship service faith is communicated through various communicative actions by means of which symbolic communication on all levels is established. The worship service itself is an encompassing communicative action aimed at orientation, expression, change and commitment. The Triune God is the foundation of the worship service and the point of orientation. The love and presence of Jesus Christ through the working of the Holy Spirit are the conditions under which the expression of faith takes place and all communicative actions become performative. Through these actions commitment is brought about, participants come to a new understanding of faith, and fundamental change is experienced.
\end{abstract}

Opsomming

Veni, veni, o Oriens ... die erediens as kommunikatiewe handeling gerig op oriëntering, uitdrukking, verandering en verbintenis

Deur simboliese kommunikasie in die erediens word geloof bemiddel en die Christelike tradisie oorgedra. In hierdie artikel word aangetoon 
dat geloof deur ' $n$ verskeidenheid kommunikatiewe handelinge in die erediens gekommunikeer word. Die erediens self is 'n omvattende kommunikatiewe handeling wat gerig is op oriëntering, uitdrukking, verandering en verbintenis. God Drie-enig is die grond van die samekoms en die oriënteringspunt. Deur die kommunikatiewe handelinge vind geloofsuitdrukking plaas. Die liefde en teenwoordigheid van Jesus Christus deur die werking van die Heilige Gees is die voorwaardes waaronder die kommunikatiewe handelinge werksaam word en die geloof uitdrukking vind. Hierdie handelinge bring verbintenis teweeg, die deelnemers kom tot nuwe geloofsverstaan en ondervind fundamentele bestaansverandering.

Liturgiesprache ... läßt sich nicht als Information analysieren. Sie will nicht von Ereignissen berichten, Gegenstände beschreiben, Hypothesen und Theorien formulieren ... Sie ist dadurch charakterisiert, daß sie eine bestimmte Tätigkeitsform ist, daß sie etwas verwirklicht, kurz, das sie Wirkkraft besitzt. Sie ist nicht bloß ein verbaler Kommentar zu einem außer ihr liegenden Tun, sondern schon in sich selbst und durch sich selbst ein Tun (Ladriere, 1973:110).

\section{Inleiding}

Die groot vraag vir die teologie en veral vir die praktiese teologie is dié oor die bemiddeling van die Christelike geloof - in die besonder die oordrag of kommunikasie van die Christelike geloof in die erediens. In aansluiting by Heitink (1993) en Pieterse (1993) se kommunikatiewe handelingsteorie word die erediens in hierdie artikel gedefinieer as 'n omvattende kommunikatiewe handeling waardeur simboliese kommunikasie op alle vlakke plaasvind. Die aktiewe moment van die erediens lê in die simboliseringsmoment waar verskeie tekens, kodes, strukture en handelinge betekenis buite hulleself om verkry. Die handelingsmoment is dus méér as taal of 'n dialogiese moment: dit genereer die simboliseringsekwens wat wêrelde buite sigself betrek. Die erediens as geheel kan as kommunikatiewe handeling omskryf word, omdat dit op die simboliseringsvlak funksioneer en gerig is op (geloofs)oriëntering, (geloofs)uitdrukking, gedragsverandering of geloofsvernuwing, verbintenis of geloofsbevestiging. In aansluiting by wat Habermas (1982) as 'n heersersvrye en magsvrye kommunikasiesituasie definieer, word die kommunikasiesituasie binne die erediens ook as sodanige heersersvrye en gelykwaardige situasie gestel, wat slegs kan geskied onder voorwaarde van die teenwoordigheid van Jesus Christus en deur die werking van die Heilige Gees. 


\section{Die oordra van die Christelike geloof - 'n prakties- teologiese handelingsteorie}

Heitink (1993:105; 146-166) definieer praktiese teologie as "de empirisch-georiënteerde theologische theorie van de bemiddeling van het christelijk geloof in de praxis van de moderne samenleving". Hierdie teorie kan soos volg omskryf word:

\section{Empiries georiënteerde teorie}

Onder "empiries georiënteerde teorie" verstaan Heitink 'n praktiese teologie waar die ervaringswêreld van mense en die situasie van kerk en samelewing, die empiriese gegewens, ernstig geneem word. Hy gaan uit van ' $n$ tweërlei praxisbegrip waarvolgens praxis 1 die "bemiddeling van die Christelike geloof" en praxis 2 die praxis van die "moderne samelewing" is. In praxis 1 is die "objek" van die praktiese teologie ter sprake en in praxis 2 die konteks waarbinne die handeling plaasvind, dus die "moderne samelewing", waarbinne ook godsdienstige en kerklike handeling as vorme van betekenisvolle sosiale en menslike handeling gesitueer kan word. Praxis 1 en praxis 2 is voortdurend op mekaar betrokke en gryp in op mekaar. Die een kan nooit los van die ander beskou word nie. Praxis is ook nie bloot praktyk nie, maar is 'n teoriegelade begrip vanweë die waardes, norme en belange wat ter sprake kom (Van der Ven, 1993:10). Die praxis van die samelewing is eeue lank beïnvloed deur die Christelike tradisie. Verder het die Christelike tradisie die eeue deur die invloed van uiteenlopende ontwikkelings in die samelewing ondergaan. Die bemiddeling van die Christelike geloof (praxis 1) in die eietydse samelewing (praxis 2) het egter problematies geword (Heitink, 1993:27).

\section{Die oordra van die Christelike geloof}

Die oordra van die Christelike geloof hang saam met die kern van die Christelike geloofsoortuiging: die kom van God tot die mens in sy leefwêreld. Dit is 'n gebeure wat voortdurend en telkens opnuut deur middel van menslike diens plaasvind (Heitink, 1993:20; Firet, 1987:31). God se handeling deur bemiddeling van menslike handeling, vorm die teologiese swaartepunt van die praktiese teologie. Die voortgang van die Christelike geloof in die lewe van mense en binne die kerk, is afhanklik van "oorlewering", die deurgee van die tradisie via uiteenlopende kanale. Hierdie oordrag vind plaas via verskillende vorme van kommunikasie of handeling. Handeling staan altyd binne 'n maatskaplike konteks en is dus altyd intersubjektiewe gebeure. Die vraag van veral die praktiese teologie is hoe kommunikasieprosesse so kan verloop en hoe strukture so ingerig kan word dat daar waarlik van die kommunikasie en oordrag van die Christelike tradisie sprake is. Om kommunikatief in diens van die 
evangelie te handel word tans as 'n algemeen aanvaarde paradigma van die praktiese teologie beskou. Die kommunikatiewe handeling "is gericht op het reeds en nog niet van het Rijk Gods, in de dialectiek van anamnese en anticipatie, van gedenken en verwachten. Dit geeft aan handelen, verstaan als intentioneel en mediaal handelen, een eigen inspiratie en motivatie mee" (Heitink, 1993:153).

\section{Die erediens as kommunikatiewe handeling}

In die (praktiese) teologie is die leer ten opsigte van die erediens van die begin af binne die raam van ' $n$ handelingsteoretiese konsep ontwikkel. Friedrich Schleiermacher het naamlik sy teorie van die erediens vanuit die onderskeiding tussen die werksame (funksionele) en die daarstellende (simboliese) handeling ontwikkel. Hy het egter ook aangetoon dat die teenstelling tussen die twee nie absoluut is nie, omdat 'n mens deurgaans kan sê: "jedes darstellende Handeln werde zugleich ein wirksames seyn und umgekehrt" (Schleiermacher, 1983:95). Die mees bepalende uitspraak wat egter vandag nog in handelingsteoretiese ontwerpe nawerk, is die volgende: "Die Geschäftsthätigkeit geht allemal auf einen Effekt aus der außer der Thätigkeit selbst liegt. Das erhöhete Bewußtsein ist nicht anderes als die Thätigkeit selbst" (Schleiermacher, 1983:71). Die handeling is gerig op 'n effek of gevolg wat buite die handeling self lê. Die verhoogde bewussyn is niks anders as die handeling self nie. Dit beteken dat die handeling self al 'n simboliese waarde of meerwaarde het - dit is reeds "verhoogde bewussyn".

Die wesenlike vraag in die oordrag van die evangelie is hoe hierdie geloofsgebeure plaasvind en onder watter voorwaardes dit geskied. God self tree in 'n verhouding met die mens, maar deur die menslike handelinge binne hierdie verhouding maak God Homself bekend. Die konteks van hierdie verhouding is die geloofsgemeenskap soos dit veral tot gestalte kom in die erediens. Die erediens is "divine and human interaction" (Wolterstorff, 1992:299). In die erediens is die gemeente in (simboliese) kommunikatiewe handelinge met God, met mekaar en met die samelewing betrek. Hierdie betrokkenheid geskied rondom die Bybelteks en met die oog op die voortgang van die geloofstradisie binne die eietydse konteks. In die handelinge van die Christelike geloofsgemeenskap is gedeelde begrip moontlik, omdat die lede van die gemeenskap verbind word deur die gemeenskaplike saak, naamlik die evangelie van Jesus Christus. Kommunikatiewe handelinge in diens van die evangelie is dus gerig op die totale omgang, verhoudinge, reaksie en optrede in woord en daad tussen God en mens, en tussen gelowiges onderling ook met die oog op die samelewing. 
Die doel van die kommunikatiewe handelinge van die erediens en die erediensgebeure as geheel is nie informasie oor God nie, maar die response of faith - "knowing a person is basically different from knowing about a person" (Hopper, 1987:71; my kursivering - EK). God self moet in waarheid ontmoet word. Hierdie belewenis van waarheid volg op die verkondiging (kommunikering) dat Jesus die Christus is en só kom die gemeenskap van gelowiges tot stand. Die hoorders in die kerk is dus min of meer "ingewydes" (Dingemans, 1991:36). Hulle kom met bepaalde verwagtings wat deur die evangelie en die verkondiging self gewek is verwagting op 'n bestaansverheldering of geloofsverdieping met die oog op 'n bestaansverandering - "a fundamental change to greater wholeness" (Hopper, 1987:88). Deur die kommunikatiewe handelinge en liturgiese gebeure as geheel kom die hoorder of gemeente tot 'n ontmoeting met Christus en kom só tot 'n nuwe selfverstaan. 'n Nuwe selfverstaan lei tot bestaansverandering of gedragsverandering en 'n nuwe lewe in Christus.

Geloof is dus nie bloot intellektuele instemming op leerstellings of ' $n$ willekeurige en irrasioneel emosionele verbondenheid nie, maar is ten diepste ervaring of belewenis - die ervaring dat Jesus die Christus is. Met betrekking tot religieuse ervaring wys Weima (1981:45-51) op die onderskeid tussen ekstrinsieke en intrinsieke religiositeit. Ekstrinsieke religiositeit gaan gepaard met vooroordele, waarvan daar egter geen sprake is wanneer godsdiens geïnternaliseer word tot persoonlike lewensoortuiging nie. In die eerste geval is slegs sprake van 'n objektiewe, leerstellige en dikwels outoritêre geloof. In die tweede geval groei 'n mens tot 'n deurleefde geloof (en groei impliseer ook verandering). "Door de bevrijding heen zijn wij opnieuw verbonden met de nog-niet-bevrijden" (Jager, 1988:161). Hier lê die kritieke moment in die spreke oor religieuse ervaring: in die ervaring word die kognitiewe moment met die affektiewe moment verbind sodat dit saam die geloofservaring vorm. Moltmann (1988) wys ook op Schleiermacher se wesenlike bydrae om die (geloof)spreke oor God te bevry van dogmatiese bewerings en moralistiese postulate:

Nicht in den objektiven geschichtlichen Fakten, sondern im subjektiven Bewußtsein des geschichtlichen Menschen ist Gott präsent. Auf der anderen Seite befreite er [Schleiermacher] den Glauben von dogmatischen Behauptungen und moralischen Postulaten und siedelte inn im Herzen der menschlichen Person an als inwendige 'Gefühl der schlechthinnigen Abhängigkeit' vom Gott (Moltmann, 1988:65-66).

Schleiermacher omskryf sy begrip das schlechthinnige Abhängigkeitsgefühl as responderende ervaring - ervaring wat bestaan in terme van 
die menslike selfbewussyn van om totaal van God afhanklik te wees (Clements, 1987:38). Dit is dus nie 'n vae afhanklikheid nie, maar 'n seker afhanklikheid. Dit beteken dat die sekerheid van geloof nie in die mens self óf in die menslike handeling lê nie, maar geleë is in die lewende ontmoeting met God deur sy Gees. Hierdie ontmoeting word bepaal deur die norm van die evangelie van Jesus Christus en vind onder meer plaas deur simbolies-kommunikatiewe handelinge in die erediens en die erediens self as omvattende kommunikatiewe handeling.

\title{
4. Die erediens as pneumatiese handeling: die gemeente as kommunikatiewe ruimte van die Heilige Gees.
}

\begin{abstract}
And might not this 'something else' be the living address of the Word of God spoken and responded to in faith, which is indeed present in, experienced by, and celebrated in the liturgical act, but in no way bound to that act but bound instead to the Spirit of God? (Johnson, 1993:222).
\end{abstract}

Die bron en waarborg van alle kommunikatiewe handelinge in die erediens is God self deur sy Gees. Die Heilige Gees gee aan mense die bevoegdheid en krag om in sy diens te handel. Van Ruler (1965:100; vgl. ook Van den Beek, 1996:7) betrek die relasie God-mens op die aspek van die werk van die Gees: "De Geest handelt nooit alleen, maar steeds met inschakeling van de mens, áls mens". Alle menslike kommunikatiewe handelinge in diens van die evangelie word deur die Gees moontlik gemaak. Die Gees maak dit moontlik, omdat die Heilige Gees die mens vryheid, verantwoordelikheid en kreatiwiteit gee. Die dinamiese erediensgebeure is dus veral pneumatiese gebeure, omdat die Heilige Gees self die kommunikator is wat egte kommunikasie moontlik maak en egte geloofsontmoeting bewerkstellig. Wanneer hierdie rol van die Heilige Gees erken word, asook die grootse kommunikatiewe moontlikhede wat daaraan ten grondslag lê, kan die kommunikasie van en deur die Heilige Gees ook nooit beperk word tot één vorm soos die rasionele, die gesproke woord en argumentvoering op kognitiewe vlak nie.

Die werking van die Gees open die ruimte vir (geloofs)ervaring en geloofsuitdrukking in en deur die geloofskommunikatiewe handeling. Die gemeente self is die kommunikatiewe ruimte van die Gees. Die gemeente as kommunikatiewe ruimte waarin die Gees lewegewend skep, getuig, lei, troos, word in die Bybel uitgedruk deur die metafoor "tempel" (vgl. McFague, 1983 wat aandui dat metaforiese taal oor God 'n getuienis is van hoe mense in die teenwoordigheid van God lewe). In die metafoor 'tempel' word die gemeente as die ruimte van God beskou - 'n geestelike huis waarin God woon (Ef. 2:19, 21-23). Met hierdie metafoor word aangedui dat God ons Vader en Jesus sy unieke Seun is. In die 
geloof en op grond van die Heilige Gees kry ons aan sy kindskap deel en word kinders van God, broers en susters van Jesus Christus en van mekaar. Hierdie broers en susters kommunikeer met mekaar, omdat hulle mekaar liefhet en verstaan (vgl. Venter, 1996). Die gemeente is 'n gemeente in kommunikatiewe ko-eksistensie wat deur die Heilige Gees moontlik gemaak word.

Kommunikatiewe handelinge in diens van die evangelie geskied as gebeure - die gebeure tussen God en mense en gelowiges onderling. Kommunikatiewe handeling is op ontmoeting gerig en is as sodanig ontmoetingsgebeure. Kommunikatiewe handelinge is gerig op die verstaan van die werklikheid, maar ook op die verstaan van die ander en van mekaar. Deur die toewending na mekaar in liefde, in die naam van Christus en deur die werking van die Heilige Gees, kan 'n mens die eie identiteit vind en waarlik mens word. Deur die ontmoeting met God kom ons dus eers tot ware selfverstaan, omdat ons binne die gemeente, deur middel van kommunikatiewe handelinge, ook ons identiteit as gelowiges vind. Die kommunikasie deur kommunikatiewe handelinge is naas die kommunikasie met God, gerig op die kommunikasie van gelowiges onderling en die vorming van die geloofsgemeenskap. Die gemeenskap van gelowiges kom nie voort uit 'n algemeen menslike poging om tot onderlinge begrip te kom en handelinge te koördineer nie, maar is geleë in die verbondenheid aan Christus:

De kerk als gemeenschap vindt haar oorsprong en bestemming niet in de gemeenschap die ze zelf vormt, maar in de participatie van ieder van de leden aan Christus. De deelname aan Christus vormt het fundament en het doel van de gemeenschappelijkheid en verbondenheid van de kerk. De kerk als gemeenschap bestaat bij gratie van de gemeenschap die Christus haar gratuïteit aanbiedt en sticht (Van der Ven, 1993:236).

In aansluiting by Habermas (1982 II:171 e.v.) se ontleding van die verhouding tussen sisteem en leefwêreld, plaas Bäumler (1984) die gemeente op die raakvlak van maatskaplike sisteme en die daaglikse leefwêreld van die lede. Dit gaan in die kommunikatiewe handeling daarom dat die deelnemers leer om die praktyk van die handeling as die proses van die krities-konstruktiewe bemiddeling van sisteem en die leefwêreld "in die perspektief van die verwerkliking van geskenkte vryheid te begryp" (Bäumler, 1984:53). Deur hierdie vryheid word die gemeente die "gemeente van bevrydes" (vgl. Jager, 1988 hierbo). In dié Leitgedanke kom tot uitdrukking dat die gemeentelede hulle vryheid nie aan hulleself te danke het nie, maar dat dit gaan om die geskenkte vryheid wat in 'n nuwe lewe verwerklik moet word. Daarmee word tegelykertyd duidelik gestel dat ten opsigte van die begrip gemeente van 
die bevrydes, nie slegs 'n formele onderskeid gemaak word wat maar met willekeurige inhoud gevul kan word nie, maar dat dit streng op die inhoudelike bepaling van die evangelie betrek moet word (Bäumler, 1984:43). God lê beslag op die mens se hele lewe en eis van die mens telkens opnuut bepaalde keuses - om op te staan en vanuit die nuwe lewe in vryheid te handel. Die kommunikatiewe handelinge moet ooreenstem met die gees van liefde van Jesus Christus, naamlik vrye, gelykwaardige en toegeneë optrede: "Der Leitgedanke der Freiheit realisiert sich in bestimmten Spielregeln der Kommunikation: 'Offenheit, Herrschaftsfreiheit, Partizipation, Solidarität'” (Bäumler, 1984:44). Hierdie wyse van kommunikasie is ook slegs moontlik onder voorwaarde van die werking van die Heilige Gees.

\section{Kommunikatiewe handeling as simboliese kommunikasie - oriëntering, ekspressie, verandering en verbintenis}

In de dagelijks leven verloopt het overgrote gedeelte van de bewuste communicatie via de taal. Dat daarnaast ook een belangrijk deel van de informatie die wij dagelijks verwerken via beelden verloopt, word meestal onderschat. Bedenken we echter dat 'beeldvorming' een belangrijk deel van ons communicatieve handelen omvat, dan maakt alleen het begrip al duidelijk dat hier van meer dan alleen communicatie met behulp van taal sprake is (Hahn \& Hoekstra, 1991:29).

Die erediens is ' $n$ kompleks van vorme, kodes en handelinge wat betekenis buite hulleself om dra en wat verlede, hede en toekoms in 'n kreatiewe spanning omsluit. Dit nooi die gemeente uit tot mee-handeling, tot duiding, tot betekenisgewing. Die simboliese kwaliteit van die erediens stel menslike kreatiwiteit by die deelnamers vry (Josuttis, 1991: 28). Kommunikatiewe handelinge is dus nie bloot vorms van dialogiese kommunikasie, wat meestal op verbale vorms aangewese is nie, maar dit gaan in die kommunikatiewe handeling om die bemiddeling van veral simboliese waarhede wat juis ander vorms van mededeling ontwyk. Dit is sodoende te onderskei van die (veral kognitief-) instrumentele handeling. Die instrumentele of funksionele aspek van die erediens moet in verhouding staan met die kommunikatiewe of simboliese aspek.

In die erediens word die daarstellende, kommunikatiewe handeling van die kerk as openbare simboliese kommunikasie van die Christelike ervaring in die medium van Bybelse en kerklike oorlewering voltrek. As fees van die bevryding en versoening is die erediens gerig op oriëntering, uitdrukking, verbintenis (versekering of bevestiging) en vernuwing van die geloof (Cornehl, 1974:460; 1979:186). Die geloof bied oriëntering, naamlik die teenwoordigheid en werksaamheid van die Drie- 
enige God, waarsonder geen sinvolle, doelgerigte handeling moontlik is nie. Die erediens bied die moontlikheid tot die openlike daarstelling van hierdie oriënteringswete deur die "simbolische Representation, dramatische Inszenierung und verbindliche Interpretation" (Cornehl, 1979:18182). Dit is belangrik om op hierdie verbintenis te let: simboliese representasie, dramatiese uitbeelding en gehoorsame of bindende interpretasie. Dit is begrippe wat van mekaar onderskei kan word, maar wat nie geskei kan word nie. In die erediens vorm dié aspekte 'n sterk verbinding, want deur die dramatiese uitbeelding of kommunikatiewe handeling vind simboliese uitdrukking plaas. Hierdie handeling of uitdrukking vra om bindende interpretasie of bevestiging, met ander woorde verdere (simboliese) handeling of gestaltegewing wat onder meer ook die etiese handeling insluit.

Deur die geloofsuitdrukking kan gevoelens, verlange, angste en wense geartikuleer word. Die gelowiges kom met hul klag, hul protes, hul rou, maar ook met hul vreugde, hul geluk, hul dank, hul lof, hul bevryding (vgl. Bäumler, 1984). "Gottesdienst als Feier der Befreiung reklamiert eine für die Bewahrung der Humanität in der Arbeitsgesellschaft unverzichtbare, allgemeine Relevanz" (Cornehl, 1974:462). Liturgie as uitdrukkingshandeling vrywaar die erediens van die moment van ondoelmatigheid. In die deurwerk van grondliggende negatiwiteite soos leed, skuld en dood, volg bevestiging of verbintenis. Versekering, versoening en vernuwing gebeur in die voltrekking van die eredienshandeling. So gebeur dit dat ervarings en verwagtings handelend en singewend tot gestalte gebring en daarmee deelname en medevoltrekking bewerkstellig word.

Gestaltegewing (vgl. ook Hahn \& Hoeksra, 1991) is dus ook 'n sleutelbegrip ten opsigte van die doelstelling en gevolg van die kommunikatiewe handeling: die kommunikatiewe handeling wil die teenwoordige betrek en tot deelnemer maak in die proses van simboliese en konkrete betekenisgewing. Deur die kommunikatiewe handeling word geloof en die geloofstradisie gekommunikeer en so vind bestaansverandering én gedragsverandering plaas. Groei in die geloofsgemeenskap in, vind juis as gevolg van (simboliese) meedoen plaas. Dit gaan dus om veel meer as die "blote" hoor of nasê van 'n saak. In en deur die kommunikatiewe handeling word passiwiteit oorkom, en medehandeling in gehoorsaamheid, asook oortuigde toewyding (commitment) aan die evangelie van Jesus Christus bewerk.

Ritual participation ... does not merely present the tradition; it enacts it. It claims not merely one's attention but one's commitment. It is self-involving. In participating, one gives oneself over to the con- 
ventions of a given community, adopting and appropriating the values, the myth, the Weltanschauung embodied in the rite. In ritual, above all, one appropriates the tradition in condensed, symbolic form ... (Searle, 1991:224 - my kursiverings - EK).

Die erediens as kommunikatiewe handeling is dus gerig op die simboliese kommunikasie van die Christelike geloof. In die erediens vind oriëntering plaas in dié sin dat die teenwoordiges gelei word tot reflektiewe nadenke en selfrefleksie: die eie identiteit en geloofsidentiteit moet bepaal en georiënteer word ooreenkomstig die Waarheid wat teenwoordig is - wat "aan die woord is" en wat die grond vir die samekoms vorm. Die erediens is dus nie maar 'n samekoms van mense met dieselfde belange of belangstellings nie. In die erediens kom die gans andere gemeenskap saam - dit is die geloofsgemeenskap wie se saamwees gegrond is in God Drie-enig en wie se samekoms gerig is op God Drie-enig. Die grond en rigtingwyser, die oriënteringspunt, is God Drie-enig.

Die oriënteringspunt, God Drie-enig, kom op 'n verskeidenheid wyses tot uitdrukking. Hy kom in die erediens tot uitdrukking deur middel van die woorde en handelinge van die liturge en gelowiges wat doen. Die moontlike uitdrukkingskrag (verhoogde spreke) is egter juis in die meerwaarde van hierdie menslike woorde en handelinge geleë (vgl. Schleiermacher, 1983 [1850] voorafgaande). Deur die simboliseringswaarde of uitdrukkingswaarde van alle kommunikatiewe handelings (sang, spreke, visuele uitbeeldings, fisieke handelings en dies meer) kom God tot uitdrukking. Die gelowiges kom egter self ook tot uitdrukking - hulle gee uitdrukking aan hulle geloof, en hulle gee ook self-ekspressie deur simboliese handelinge. Die eie identiteit, die geloofsidentiteit word dus tot uitdrukking gebring. Deur die werking van God se uitdrukkingskrag én gelowiges se self-ekspressie kom hulle tot selfherkenning en tot nuwe selfverstaan. Hierdie selfherkenning dwing die gelowige tot verandering en vernuwing, tot heroriëntering in die lig van die oriënteringpunt, God. So word daar tot nuwe geloofsverstaan gekom en vind ook identiteitsveranderings plaas. Dit lei tot nuwe geloofsuitdrukking. Die gelowige word voortdurend omvorm en nuut gevorm deur God wat Homself tot uitdrukking bring - God wat deur die kommunikatiewe handelinge in die erediens en die kommunikatiewe handeling van die erediens werk. Ons glo dat hierdie werksaamheid deur die Heilige Gees plaasvind. So word alle menslike handelinge oorstyg, verkry dit meerwaarde, en word die simboliese handelinge ware geloofshandelinge, kommunikatiewe handelinge. 


\section{Samevatting}

Die aktiewe moment van die erediens lê in die simboliseringsmoment waar die handelinge buite hulleself om betekenis verkry. Dit genereer die simboliseringsekwens wat wêrelde buite sigself betrek. Deur die kommunikatiewe handeling word die teenwoordiges in die erediens uitgenooi tot medehandeling, deelname en geloofsuitdrukking. Die handelinge nooi die gemeente uit tot duiding, tot betekenisgewing. Deur konkrete deelname kan die deelnemer werklik kommunikeer, hom/ haarself oriënteer, uitdruk, en deur die deelname aan die handeling, ook verander word. So word die deelnemer gelowige, en word die gelowiges omvormde gelowiges. Deelname aan geloofshandelinge is dus meer as nadenke oor 'n godsdiens of 'n geloof. Deelname vorm geloof en vereis gedragsverandering, nuwe geloofsgedrag en voortgaande geloofshandeling. Deelname aan die simboliese daarstelling en handelende uitbeelding verg verbintenis (commitment) en lei tot toe-eiening en bevestiging van die geloof.

Dit blyk dus onteenseglik dat gewaak moet word teen passiwiteit en stagnasie in die erediens. Taal, musiek en ander uitdrukkingsvorme moet op 'n kreatiewe wyse aan die gelowiges gebied word sodat hulle tot aktiewe deelname en simboliese ekspressie uitgenooi en aangespoor word. Omdat deelnemers in die erediens voortdurend tot nuwe verstaan, nuwe selfverstaan en gedragsverandering in die lig van God se werklikheid moet kom, behoort nuwe en vernuwende vorme van handeling as kreatiewe uitdrukkingsmiddele wat aktiewe deelname, verbintenis en toewyding verg, voortdurend ondersoek te word. Sinvolle liturgiese vernuwing mag dus nie geïgnoreer word nie. Daar moet egter steeds gewaak word teen handelinge wat so eksplisiet raak en so aan die alledaagse geörienteerd is dat die simboliese meerwaarde ontbreek of verlore gaan. Alle menslike handelinge, ook dié van die erediens, is sinloos en rigtingloos sonder dié oriënteringspunt, dié lig waarmee ons deurstraal moet word ten einde tot nuwe verstaan en nuwe selfverstaan te kom en waarop ons ons voortdurend biddend moet rig:

Veni, veni, o Oriens; solare nos adveniens ...

O kom, o kom, o Dag wat breek, om lig in ons nou aan te steek.

Verby is nagte sonder moed, want in die ooste skyn u gloed ... (Liedboek van die Kerk, 2001:318).

\section{Bibliografie}

BÄUMLER, C. 1984. Kommunikative Gemeindepraxis: Eine Untersuchung ihrer Bedingungen und Möglichkeiten. München : Kaiser.

CLEMENTS, K.W. 1987. Friedrich Schleiermacher: Pioneer of modern theology. London : Collins. 
CORNEHL, P. 1974. Gottesdienst. (In Klostermann, F. \& Zerfass, R. Praktische Theologie heute. München : Kaiser. p. 447-465.)

CORNEHL, P. 1979. Theorie des Gottesdienstes - ein Prospekt. Theologische Quartalschrift, 159:179-196.

DINGEMANS, G.D.J. 1991. Als hoorder onder de hoorders: Hermeneutische homiletiek. Kampen : Kok.

FIRET, J. 1987. Spreken als een leerling. Praktisch-theologische opstellen. Kampen : Kok.

HABERMAS, J. 1982. Theorie des kommunikativen Handelns I \& II. Frankfurt : Suhrkamp.

HAHN, J.G. \& HOEKSTRA, H. 1991. Een gesprek over film en televisie: over de theorie en de praktijk van 'het mediagesprek'. Kampen : Kok.

HEITINK, G. 1993. Praktische Theologie: geschiedenis, theorie, handelingsvelden. Kampen : Kok.

HOPPER, J. 1987. Understanding modern theology II: Reinterpreting Christian faith for changing worlds. Philadelphia : Fortress.

JAGER, O. 1988. De verbeelding aan het woord. Pleidooi voor een dichterlijker en zakelijker spreken over God. Baarn : Ten Have.

JOHNSON, M. 1993. Liturgy and theology. (In Bradshaw, P. \& Spinks, B., eds. Liturgy in dialogue. London : SPCK. p. 202-225.)

JOSUTTIS, M. 1991. Der Weg in das Leben: Eine Einführung in den Gottesdienst auf verhaltenswissenschaftlicher Grundlage. München : Kaiser.

KLOPPERS, E.C. 2001. O kom, o kom, Immanuel. (In Liedboek van die Kerk. Kaapstad : NG Kerk-Uitgewers. Lied 318.)

LADRIERE, J. 1973. Die Sprache des Gottesdienstes. Die Performativität der Liturgiesprache. Concilium, 9:110-125.

LIEDBOEK VAN DIE KERK. 2001. Kaapstad : NG Kerk-Uitgewers.

MCFAGUE, S. 1983. Metaphorical theology: models of God in religious language. London : SCM.

MOLTMANN, J. 1988. Was ist Theologie heute? Zwei Beiträge zu ihrer Vergegenwärtigung. Basel : Herder.

PIETERSE, H.J.C. 1993. Praktiese teologie as kommunikatiewe handelingsteorie. Pretoria : RGN-Uitgewers.

RICOEUR, P. 1991. Tekst en betekenis. Opstellen over der interpretatie van literatuur. Baarn : Ten Have.

SCHLEIERMACHER, F.D.E. 1983 [1826/27]. Christliche Sittenlehre. Einleitung. Hrg. von Peiter, H. Stuttgart : Kohlhammer.

SCHLEIERMACHER, F.D.E. 1983 [1850]. Die praktische Theologie nach den Grundsätzen der evangelischen Kirche. Berlin : Kohlhammer.

SEARLE, M. 1991. Two liturgical traditions: Looking to the future. (In Bradshaw, P.F. \& Hoffman, L.A., eds. The changing face of Jewish and Christian worship in North America. Notre Dame : University of Notre Dame Press. p. 221-243.)

VAN DER VEN, J. 1993. Ecclesiologie in context. Kampen : Kok.

VAN DEN BEEK, A. 1996. Spiritualiteit: Een must voor theologen? Gereformeerde Theologische Tijdschrift, 96(1):3-10.

VAN RULER, A.A. 1965. Reformatorische opmerkingen in de ontmoeting met Rome. Hilversum : Gooi \& Sticht.

VENTER, C. 1996. Uitkringende liefdesbetoon. Kommunikatiewe handelinge in diens van die onderlinge liefdesgemeenskap in die kerk. Pretoria : RGN-Uitgewers.

WEIMA, J. 1981. Reiken naar oneindigheid. Inleiding tot de psychologie van de religieuze ervaring. Baarn : Ten Have Weima. 
WOLTERSTORFF, N. 1992. The Reformed liturgy. (In McKim, D.J., ed. Major themes in the Reformed tradiditon. Grand Rapids : Eerdmans. p. 273-304.)

\section{Kernbegrippe:}

erediens

geloofsuitdrukking

kommunikatiewe handeling

oriëntering

simboliese kommunikasie

verbintenis

\section{Key concepts:}

commitment

communicative actions

expression of faith

orientation

symbolic communication

worship service 
Veni, veni, o Oriens ... die erediens as kommunikatiewe handeling ... 